\title{
The effects of treatment with felodipine as a single agent in coronary artery disease
}

\author{
M J METCALFE, N S CHAN-WAH-HAK, K JENNINGS \\ From the Cardiac Department, Aberdeen Royal Infirmary, Foresterhill, Aberdeen
}

SUMMARY In an earlier study one dose of the vasodilator felodipine improved haemodyna $\vec{\omega}_{\mathrm{wic}}$ function in patients with angina without having a negative inotropic effect. The haemodynaminic response of sustained treatment with felodipine as a single agent in stable angina was investigatedin a double blind crossover study of 25 patients. The dosage of felodipine was increased from 5 ing twice daily to $10 \mathrm{mg}$ twice daily after two weeks. Twenty one patients completed the study, t్రీ0 were withdrawn because of acute myocardial infarction, and a further two because of symptoms of vasodilatation. Felodipine reduced both supine and erect blood pressure and increased the resting heart rate. Median exercise time was increased by $10 \%$ at two weeks and $7 \%$ at four weeks. There was a sustained reduction in the number of angina attacks and use of sublingual nitrate on acthe treatment.

Felodipine has antianginal effects but these are limited and seem less than those of other relaffed compounds. This finding is unexpected and possibly related to increased heart rate.

Felodipine, a dihydropyridine, is a new vasodilating agent which reduces blood pressure, increases stroke volume, and in a single dose study increased exercise capacity. ${ }^{1}$ It has also been shown to be a useful adjunctive agent to $\beta$ blockade in stable angina. ${ }^{2}$ To investigate the potential beneficial effects of longer term treatment we studied the effects of an increasing dose of felodipine on exercise tolerance, symptoms, and the haemodynamic response to exercise.

\section{Patients and methods}

We studied 25 patients ( 17 men and eight women, aged 40-65 years (mean 52.0)) who had had stable angina for at least two months with at least five attacks per week. All patients had an initial positive exercise test with at least $1 \mathrm{~mm}$ of ST depression associated with chest pain. They gave their informed consent to the study. Fertile women were excluded. We also excluded patients with important valve disease, myocardial infarction within the past two months, unstable angina, systolic blood pressure < $100 \mathrm{~mm} \mathrm{Hg}$, insulin dependent diabetes, a history of severe allergic response, or severe hepatic failure.

Requests for reprints to Dr M J Metcalfe, Cardiac Department, Aberdeen Royal Infirmary, Foresterhill, Aberdeen AB9 2ZB.

Accepted for publication 19 December 1988
All medication other than sublingual nitrates stopped for at least two weeks before the start of ghe study. Seven patients had already been treated ofth nifedipine and three with atenolol.

The study had three parts-a run in period of $\overrightarrow{\mathrm{E}}$ wo weeks on placebo followed by two double bPind crossover periods of four weeks on felodipine placebo. After two weeks we increased the dose-of either felodipine or placebo from $5 \mathrm{mg}$ twice a da to $10 \mathrm{mg}$ twice a day if no adverse features Had occurred. The tablets taken during the felodipine and placebo treatment periods were dispensed in cợnputer generated random order. After the first and second two week periods the patients performe a symptom limited Bruce protocol exercise test find had a clinical examination with history. The esect and supine blood pressure and pulse were carefuly recorded. All exercise tests were performed between 1 and 3 hours after the last dose of the study medication. Plasma samples were taken for felodipine analysis at each visit during the crossoffer period.

At each visit the patients were given a diary card to record the number of angina attacks and consurifption of sublingual nitrate. At the end of the study? the patients returned to their usual medication.

Results are expressed as median or mean and wore analysed by Wilcoxon matched pairs signed ramks test and Student's $t$ test; a probability value of < 005 was regarded as statistically significant. 


\section{Results}

Twenty one patients completed the study. Of the four patients who were withdrawn from the study: one experienced severe abdominal pain while on placebo, one complained of flushing and burning of her feet, legs, and face while taking felodipine, and an acute myocardial infarction developed while two patients were taking felodipine $5 \mathrm{mg}$ twice daily. After two weeks' treatment, 11 patients had their dosage increased from $5 \mathrm{mg}$ twice daily to $10 \mathrm{mg}$ twice daily but in one patient the dose was subsequently reduced because minor side effects of vasodilatation developed.

At the end of the double blind periods 11 patients were taking felodipine $5 \mathrm{mg}$ twice daily, 10 patients were taking $10 \mathrm{mg}$ twice daily, and 10 and 11 patients were taking $5 \mathrm{mg}$ and $10 \mathrm{mg}$ of placebo respectively. Plasma analysis showed that two additional patients had appreciable concentrations of plasma felodipine when they should have been taking placebo. We excluded their data from subsequent analysis. Data from the remaining 19 patients were analysed.

Supine and erect blood pressure were lower during felodipine treatment than during placebo treatment. The mean reductions after two weeks' treatment with felodipine were $8 / 7 \mathrm{~mm} \mathrm{Hg}(\mathrm{p}<0.01)$ and $8 / 4 \mathrm{~mm} \mathrm{Hg}(\mathrm{p}<0.05 / \mathrm{NS})$ respectively. The corresponding figures after four weeks' treatment were $3 / 5 \mathrm{~mm} \mathrm{Hg}(\mathrm{NS} / \mathrm{p}<0.05)$ and $7 / 6 \mathrm{~mm} \mathrm{Hg}$ (p < $0 \cdot 05 / \mathrm{NS})$. After four weeks of felodipine treatment the mean heart rate in supine patients increased slightly ( 6 beats $/ \mathrm{min}(p<0.05))$. After two weeks of felodipine treatment the median duration of exercise was $10 \%$ higher than during placebo treatment $(p<$ $0.05)$. The increase (7\%) after four weeks was not statistically significant (table 1 ). When patients were taking felodipine $5 \mathrm{mg}$ twice a day the mean (SD) heart rate at maximal exercise was increased by seven beats per minute (from 144 (12) to 151 (13) NS), systolic blood pressure was reduced from 165 (19) to 159 (19) $\mathrm{mm} \mathrm{Hg}$ (NS), and the mean (SD) ratepressure product was essentially unchanged (from 24500 (3700) to 23900 (3300)). When patients were taking felodipine $10 \mathrm{mg}$ twice a day, the mean (SD) heart rate increased from 149 (14) to 150 (14), the systolic blood pressure was reduced from 158 (15) to 154 (18) $\mathrm{mm} \mathrm{Hg}$ (NS), and the rate-pressure product was again essentially unchanged (from 23700 (3100) to 23400 (3300)). We did not find a significant relation between ST depression and the rate-pressure product at maximal exertion, although median ST depression was reduced after two weeks' treatment with felodipine ( 2 to $1.8 \mathrm{~mm}, \mathrm{p}<0.05$ ) but not after four weeks.

The diary cards showed a sustained tendency towards fewer angina attacks and reduced consumption of glyceryl trinitrate during treatment with felodipine (NS) (tables 2 and 3). Both systolic and diastolic blood presure fell significantly after exercise, particularly at 10 minutes $(8 / 7 \mathrm{~mm} \mathrm{Hg}, p<$ $0.01 / \mathrm{p}<0.05)$. The heart rate was also significantly increased after exercise, especially after four weeks' treatment with felodipine (at 10 minutes it was 11 beats per minute higher $(p<0.001))$. No clinically significant differences in mean body weight, angle circumference, or haematological or biochemical values were noted.

\section{Discussion}

The efficacy of calcium antagonist vasodilator agents in treating symptomatic coronary artery disease is well established both on their own and in combination with other agents such as $\beta$ blockers. Most of these agents have negative inotropic effects, which can limit their usefulness; none the less, felodipine has been shown to increase cardiac output ${ }^{34}$ and to increase resting myocardial blood flow. ${ }^{3}$ Interest has therefore been expressed in establishing its potential

Table 1 Exercise duration ( $s$ ) in different treatment groups

\begin{tabular}{|c|c|c|c|c|c|c|}
\hline & $\begin{array}{l}\text { Placebo after } \\
2 \text { weeks }\end{array}$ & & $\begin{array}{l}\text { Felodipine after } \\
2 \text { weeks }\end{array}$ & $\begin{array}{l}\text { Placebo after } \\
4 \text { weeks }\end{array}$ & & $\begin{array}{l}\text { Felodipine after } \\
4 \text { weeks }\end{array}$ \\
\hline $\begin{array}{l}\mathbf{n} \\
\text { Mean (SD) } \\
\text { Median }\end{array}$ & $\begin{array}{l}11 \\
514(148) \\
505\end{array}$ & NS & $\begin{array}{l}5 \text { mg twice a day } \\
11 \\
558 \text { (127) } \\
586\end{array}$ & $\begin{array}{l}2 \text { and } 4 \text { weeks } \\
11 \\
556(131) \\
540\end{array}$ & NS & $\begin{array}{l}11 \\
588(148) \\
595\end{array}$ \\
\hline $\begin{array}{l}\text { n } \\
\text { Mean (SD) } \\
\text { Median }\end{array}$ & $\begin{array}{l}8 \\
510(176) \\
528\end{array}$ & $\begin{array}{c}\text { Felodipine } 5 \mathrm{mg} \\
\text { NS }\end{array}$ & $\begin{array}{l}\text { day at } 2 \text { weeks and } \\
8 \\
574(141) \\
584\end{array}$ & $\begin{array}{l}0 \text { mg twice a do } \\
8 \\
537(163) \\
538\end{array}$ & week & $\begin{array}{l}8 \\
545(123) \\
530\end{array}$ \\
\hline $\begin{array}{l}\text { n } \\
\text { Mean (SD) } \\
\text { Median }\end{array}$ & $\begin{array}{l}19 \\
524(157) \\
505\end{array}$ & $p<0.05$ & $\begin{array}{l}19 \quad \text { Totals } \\
565(134) \\
586\end{array}$ & $\begin{array}{l}19 \\
548(145) \\
540\end{array}$ & NS & $\begin{array}{l}19 \\
570(140) \\
568\end{array}$ \\
\hline
\end{tabular}


Table 2 Number of angina attacks per week in different treatment groups

\begin{tabular}{|c|c|c|c|c|c|}
\hline & $\begin{array}{l}\text { Placebo after } \\
2 \text { weeks }\end{array}$ & & $\begin{array}{l}\text { Felodipine after } \\
2 \text { weeks }\end{array}$ & $\begin{array}{l}\text { Placebo after } \\
4 \text { weeks }\end{array}$ & $\begin{array}{l}\text { Felodipine after } \\
4 \text { weeks }\end{array}$ \\
\hline $\begin{array}{l}\mathbf{n} \\
\text { Mean (SD) } \\
\text { Median }\end{array}$ & $\begin{array}{l}11 \\
2 \cdot 8(1 \cdot 9) \\
2 \cdot 7\end{array}$ & NS & $\begin{array}{l}5 \text { mg twice a day } \\
11 \\
2 \cdot 2(3 \cdot 2) \\
1 \cdot 0\end{array}$ & $\begin{array}{l}\text { and } 4 \text { weeks } \\
10 \\
5 \cdot 6(6 \cdot 4) \\
2 \cdot 2\end{array}$ & $\begin{array}{l}10 \\
2 \cdot 2(3 \cdot 0) \\
0 \cdot 8\end{array}$ \\
\hline $\begin{array}{l}\text { n } \\
\text { Mean (SD) } \\
\text { Median }\end{array}$ & $\begin{array}{l}8 \\
6 \cdot 2(8 \cdot 2) \\
3 \cdot 0\end{array}$ & $\begin{array}{r}\text { Felodipine } \\
\text { NS }\end{array}$ & $\begin{array}{l}\text { day at } 2 \text { weeks and } \\
8 \\
5 \cdot 2(3 \cdot 5) \\
4 \cdot 8\end{array}$ & $\begin{array}{l}\text { mg twice a day at } 4 \text { weeks } \\
8 \\
5 \cdot 3(5 \cdot 1) \\
4 \cdot 8\end{array}$ & $\begin{array}{l}8 \\
3 \cdot 2(2 \cdot 6) \\
2 \cdot 3\end{array}$ \\
\hline $\begin{array}{l}\mathbf{n} \\
\text { Mean (SD) } \\
\text { Median }\end{array}$ & $\begin{array}{l}19 \\
4 \cdot 2(5 \cdot 8) \\
2 \cdot 7\end{array}$ & NS & $\begin{array}{l}19 \text { Totals } \\
3 \cdot 4(3 \cdot 6) \\
2 \cdot 0\end{array}$ & $\begin{array}{l}18 \\
5 \cdot 0(5 \cdot 7) \\
2 \cdot 9\end{array}$ & $\begin{array}{l}18 \\
2 \cdot 8(2 \cdot 9) \\
1.4\end{array}$ \\
\hline
\end{tabular}

for treating patients with coronary artery disease.

Single doses of felodipine increased maximal cardiac output by $20 \%$ and the maximal pressure-rate product by $13 \% .^{1}$ The relation between ST segment depression and the rate-pressure product during exercise was also favourably influenced. In a further study in which felodipine was added to conventional $\beta$ blockade there was a significant improvement in exercise tolerance and daily attacks of angina. ${ }^{2}$

In our study although there was a similar improvement in exercise tolerance after two weeks' treatment, at four weeks the benefit was less apparent. This reduced benefit is not entirely unexpected because felodipine, in common with other peripheral vasodilators, induces reflex sympathetic activity thereby increasing heart rate and myocardial oxygen consumption, with a consequent effect on the drug's antianginal action. Both supine and erect blood pressure fell significantly as would be expected with a drug causing peripheral arteriolar vasodilatation.

Despite the increase in dosage in eight $(42 \%)$ of the 19 patients at four weeks the effect of felodipine on mean exercise capacity was not as strong as at two weeks. There are two possible explanations for this. ज Firstly a ceiling may have been reached at a dose of $5 \mathrm{mg}$ twice a day, which suggests that the drug may have a flat dose response curve. This explanation is supported by the apparent lack of additional effect on the resting supine and erect blood pressure, medians ST depression, and rate-pressure product at maximal exercise after increasing the dosage to $10 \mathrm{mgo}$ twice a day. Secondly, the training effect of repeated exercise tests could improve the results of botho treatment groups; however, as the baseline exercise tolerance improves, the statistical significance of theo measured improvement is reduced. As only $42 \%$ ofo the patients had their felodipine increased to $10 \mathrm{mg} \cong$ twice a day, subgroup analysis of patients taking $\overrightarrow{\overrightarrow{0}}$ $5 \mathrm{mg}$ and $10 \mathrm{mg}$ twice a day after 4 weeks has to be $\exists$ interpreted with caution in view of the relatively? small numbers. Although an increase in the dosage of? felodipine from $5 \mathrm{mg}$ to $10 \mathrm{mg}$ twice daily did not improve exercise tolerance or the rate-pressureo product at maximal exercise, the number of weekly angina attacks was halved. The number of side effects reported was low and related to the vasodilatory properties of the drug.

Table 3 Use of sublingual glyceryl trinitrate in different treatment groups (tablets $(0.5 \mathrm{mg})$ per week)

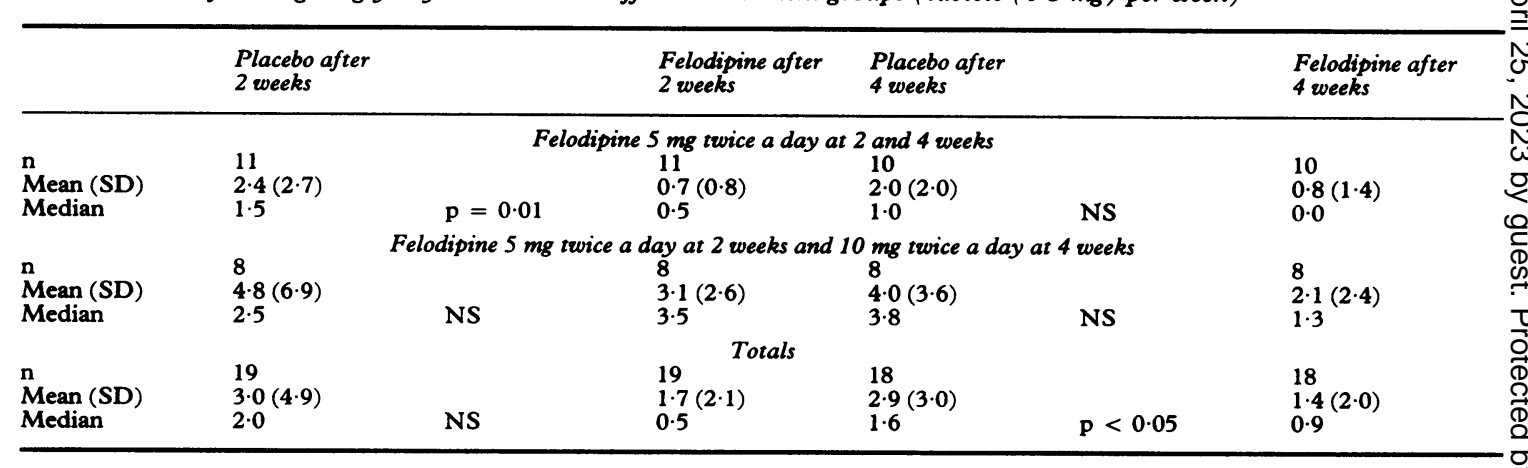


The first patient who experienced a myocardial infarction while taking felodipine had a poor initial exercise tolerance of 207 seconds and approximately three attacks of angina per day associated with exercise. During felodipine treatment exercise tolerance fell to 190 seconds and the number of anginal attacks increased by $16 \%$. It is possible that in this patient the drug contributed to the development of these adverse features because it resulted in unopposed reflex sympathetic activity (thereby increasing myocardial oxygen consumption ${ }^{2}$ or because it induced a coronary artery steal phenomenon. When it is used alone, nifedipine (a related dihydropyridine) can induce angina; the mechanism for this effect is not known. ${ }^{5}$ The second patient with a myocardial infarction had satisfactory initial exercise tolerance and approximately one anginal attack per week. Because he improved substantially on felodipine the development of infarction was unexpected, and it seems unlikely that it was related to the drug. This study shows that felodipine has antianginal properties in patients with coronary artery disease but these seem to be limited and less than those of other reported compounds such as nifedipine.$^{67}$ It may be especially suitable for patients with angina and hypertension in whom its ability to maintain or increase the cardiac output is an advantage. $^{48}$

We thank Astra Pharmaceuticals and in particular Mrs Ywonne Fox for their help with this study.

\section{References}

1 Detry JR, DeCoster PM, Renkin J. Haemodynamic effects of felodipine at rest and during exercise in exertional angina pectoris. Am J Cardiol 1983;52: 453-7.

2 Sheridan JV, Thomas P, Routledge PA, Sheridan DJ. Effects of felodipine on haemodynamics and exercise capacity in patients with angina pectoris. $\mathrm{Br} \mathrm{J} \mathrm{Clin}$ Pharmacol 1987;23:391-6.

3 Tweddle AC, Johnson G, Pringle TH, Murray RG, Hutton $I$. The systemic and coronary haemodynamic effects of felodipine in patients with coronary heart disease. Eur Heart J 1983;4:699-705.

4 Kassis E, Amtorp O, Waldorff S, Fritz-Hansen P. Efficacy of felodipine in chronic congestive heart failure: a placebo controlled haemodynamic study at rest and during exercise and orthostatic stress. $\mathrm{Br}$ Heart J 1987;58:505-11.

5 Jariwalla AG, Anderson EG. Production of ischaemic cardiac pain by nifedipine. $\mathrm{Br}$ Med $J$ 1978;276: 1181-2.

6 Moskowitz RM, Piccini PA, Nacarelli GV, Zelis R. Nifedipine therapy in stable angina pectoris: preliminary results of effects on angina frequency and treadmill exercise response. Am J Cardiol 1979;44: 811-6.

7 Lynch P, Dargie H, Krikler S, Krikler D. Objective assessment of antianginal treatment: a double blind comparison of propranolol, nifedipine and their combination. Br Med J 1980;281:184-7.

8 Culling W, Ruttley MSM, Sheridan DJ. Acute haemodynamic effects of felodipine during beta blockade in patients with coronary artery disease. $\mathrm{Br}$ Heart J 1984;52:431-4. 